\title{
Dinamap fails to detect hypotension in very low birthweight infants
}

\author{
G K DIPROSE, D H EVANS, L N J ARCHER, AND M I LEVENE \\ Department of Medical Physics and Clinical Engineering, Leicester Royal Infirmary, and Department of \\ Child Health, Leicester University Medical School
}

SUMMARY The accuracy of blood pressure measurements obtained from very low birthweight $(<1500 \mathrm{~g})$ neonates using the Dinamap oscillometric monitor was investigated. Comparisons using umbilical artery measurements showed that the monitor is less reliable in the lower pressure range and specifically that it tends to overestimate pressure in hypotensive infants.

Modern neonatal intensive care makes the chances of survival of extremely premature babies more likely than ever before, but accurate monitoring is essential to optimise management and reduce the risk of subsequent handicap. The recognition and treatment of hypotension is particularly important in this context to avoid cerebral ischaemic injury.

Blood pressure monitoring in the ill, small, newborn infant may be direct from an indwelling arterial catheter or by indirect measurement techniques. The most popular of these indirect methods relies on automatic oscillometric monitors. Their accuracy in neonatal use has been investigated and they have been found to be reliable, but their efficacy in the tiny infant has not been adequately researched. We report here the results of a comparison of blood pressures recorded by a non-invasive oscillometric monitor and direct measurement from an umbilical artery catheter in very low birthweight infants.

\section{Patients and methods}

Twelve infants of very low birth weight (median $1040 \mathrm{~g}$, range $700-1470 \mathrm{~g}$ ) and under 30 weeks' gestation were studied. Umbilical arterial catheters were inserted on the first day of life for clinical reasons (respiratory distress syndrome in 11 cases and presumed aspiration syndrome in one) and comparisons between direct arterial and Dinamap readings were performed within 10 days of birth.

A 4 FG side holed arterial catheter had its tip placed at the level of the diaphragm and was connected by low compliance tubing to an Elcomatic EM751A pressure transducer. The blood pressure waveform was recorded on a multichannel Gould chart recorder. The patency of the catheter was maintained by a continuous slow infusion $(1-3 \mathrm{ml} / \mathrm{h}$ ) of heparinised $5 \%$ dextrose solution, which was delivered by a syringe pump through an Intraflo device to maintain the frequency response of the measurement system. The use of a side holed catheter ensures that there is no kinetic energy artifact, and this configuration has previously been shown to give an almost flat frequency response up to $10 \mathrm{~Hz} .{ }^{1}$ The transducer was regularly zeroed and adjusted to be level with the middle of the chest of the baby.

A Dinamap 847 (Critikon) automatic blood pressure monitor was also used to measure indirectly the blood pressure from these 12 infants. The smallest cuff size ( $25 \mathrm{~mm}$ width) was applied according to the manufacturer's instructions to the upper arm and the Dinamap blood pressure recordings written on the chart paper alongside the direct recording at the time the Dinamap went through its measurement routine. Subsequently, the traces were analysed and only paired recordings with stable, non-damped chart recordings-that is, recordings showing appreciable high frequency components-were compared.

\section{Results}

A total of 417 paired sets of readings were obtained from the 12 infants in the study (the median number from each infant was $35 \cdot 5$, the range 17 to 44 ). The correlation coefficients between the systolic and diastolic pressures were 0.67 and 0.49 , respectively. The distribution of Dinamap readings about the intra-arterial readings is shown in the Table. Dinamap overestimates both the diastolic and the systolic 
Table Contingency tables comparing the numbers of diastolic and systolic blood pressure readings obtained using a Dinamap inflatable cuff monitor falling in a given pressure range with those from an indwelling catheter falling in the same or a different range

\begin{tabular}{|c|c|c|c|c|c|c|c|c|c|c|}
\hline \multirow{2}{*}{$\begin{array}{l}\text { Dinamap cuff } \\
\text { pressure } \\
\text { ( } m m \mathbf{m g})\end{array}$} & \multicolumn{10}{|c|}{ Intra-arterial pressure (by indwelling catheter) $(\mathrm{mmHg})$} \\
\hline & $10-14$ & $15-19$ & $20-24$ & $25-29$ & $30-34$ & $35-39$ & $40-44$ & $45-49$ & & \\
\hline $10-14$ & & 1 & 1 & & & & & & & \\
\hline $15-19$ & & 3 & 5 & 15 & 3 & 1 & & & & \\
\hline $20-24$ & & 1 & 8 & 12 & 11 & 1 & & & & \\
\hline $25-29$ & & & 18 & 38 & 13 & 3 & 1 & & & \\
\hline $30-34$ & 2 & 3 & 13 & 45 & 17 & 7 & 2 & 3 & & \\
\hline $35-39$ & & 5 & 11 & 17 & 28 & 7 & 19 & 3 & & \\
\hline $40-44$ & & & 3 & 6 & 10 & 12 & 11 & 6 & $\cdot$ & \\
\hline $45-49$ & & & & 2 & 3 & 9 & 4 & & & \\
\hline $50-54$ & & & & 1 & & 15 & 4 & & & \\
\hline $55-59$ & & & & & 1 & 8 & & 1 & & \\
\hline $60-64$ & & & 2 & & & 2 & & & & \\
\hline Systolic & $30-34$ & $35-39$ & $40-44$ & $45-49$ & $50-54$ & $55-59$ & $60-64$ & $65-69$ & $70-74$ & $75-79$ \\
\hline $30-34$ & & & 1 & 1 & & & & & & \\
\hline $35-39$ & 1 & 4 & 6 & 2 & & & & & & \\
\hline $40-44$ & & 9 & 29 & 8 & 1 & & & & & \\
\hline $45-49$ & 2 & 18 & 33 & 29 & 8 & & & & & \\
\hline $50-54$ & 1 & 13 & 16 & 18 & 21 & 3 & 1 & & & \\
\hline $55-59$ & 1 & 3 & 8 & 8 & 18 & 9 & 2 & & & \\
\hline $60-64$ & & 3 & 1 & 4 & 11 & 16 & 2 & 2 & & \\
\hline $65-69$ & & 1 & & 4 & 8 & 3 & 1 & & 1 & \\
\hline $70-74$ & & 1 & 1 & 3 & 6 & 9 & 3 & 4 & 8 & \\
\hline $75-79$ & & 2 & & & 14 & 3 & & 3 & 13 & 1 \\
\hline $80-84$ & & & & & 4 & 3 & & 1 & 2 & \\
\hline $85-89$ & & & & & 4 & 1 & & & & \\
\hline
\end{tabular}

pressure at the lower end of the pressure range covered. This tendency is much reduced when the pressures fall within what is suggested as the normotensive range $^{2}$ for these low birthweight infants.

\section{Discussion}

These results suggest that Dinamap consistently over reads the systolic and diastolic blood pressures in very low birthweight infants when hypotension occurs. Assessment of blood pressure in these infants becomes unreliable when its accurate measurement is most important. Previous reports using the Dinamap monitor in neonates claim it to be generally both accurate and reliable ${ }^{3-6}$ although Dellagramaticas and Wilson suggest that the monitor underestimates the diastolic and mean arterial pressures by approximately 10 and $20 \%$, respectively. ${ }^{3}$ Closer inspection of the diastolic pressure data, however, suggests that in the lower pressure range (diastolic pressure $<30 \mathrm{mmHg}$ ) these authors observed an overestimation of the pressure similar to that reported here. The results of PellegriniCaliumi et al also seem to bear out these findings, although actual data points are not shown. ${ }^{7}$ It thus seems that correlation between Dinamap and direct arterial pressure readings is good over a wide range of values but that if interest is restricted to the region where the arterial pressures of the hypotensive very low birthweight neonate would lie-that is, systolic pressure $<40 \mathrm{mmHg}$ - then the correlation becomes poor.

Reasons for unreliable blood pressure monitoring depend on the equipment used. If the cuff width to arm circumference ratio falls below 0.45 then there will be a fairly large error in perceived blood pressure measurement. ${ }^{4}$ Due to the tiny size of the infants' arms in this study the smallest cuff easily exceeded this ratio and is not likely to account for inaccuracies. Movement of the arm induced by triggering of the device may explain some raised measurements and this was carefully looked for but only occasionally seen. Even if movement artefact were to be responsible for the over reading of the Dinamap, the clinical importance of our observation remains. Blood pressure measured directly from the aorta may also be prone to error. Damping of the signal makes both systolic and diastolic measurements unreliable but should not greatly affect the mean arterial pressure (this is because only the higher harmonics of the waveform are affected). Care was taken in this study to compare only undamped pressure recordings from the umbilical 
catheter with the Dinamap readings. The brachial and aortic blood pressures possibly differ slightly due to either resistive pressure gradients or reflected pressure waves, but a recent study by Butt and Whyte suggests that this could not be a major source of error. ${ }^{8} \mathrm{~A}$ certain scatter in the results is to be expected because of the respiratory modulation of the blood pressure, but this manifests itself as a random error rather than a systematic error.

We believe that the Dinamap and possibly other similar oscillometric monitors are unreliable in measuring blood pressure in ill, very low birthweight infants, particularly when hypotension is present. This is the most critical time to have an accurate blood pressure recording and consistent overestimation by the Dinamap may delay the recognition and treatment of clinically important shock. Direct aortic blood pressure monitoring is both reliable and safe in this group of infants.

\section{References}

${ }^{1}$ Evans DH, Lark GM, Archer LNJ, Levene MI. The continuous measurement of intra-arterial pressure in the neonate-method and accuracy. Clin Phys Physiol Meas 1986;7:179-84.
${ }^{2}$ Versmold HT, Kitterman JA, Phibbs RH, Gregory GA, Tooley WH. Aortic blood pressure during the first 12 hours of life in infants with birth weight 610 to 4220 grams. Pediatrics 1981;67:607-13.

3 Dellagramaticas HD, Wilson AJ. Clinical evaluation of the Dinamap non-invasive blood pressure monitor in pre-term neonates. Clin Phys Physiol Meas 1981;2:271-6.

${ }^{4}$ Kimble KJ, Darnall RA, Yelderman MD, Ariagno RL, Ream AK. An automated oscillometric technique for estimating mean arterial pressure in critically ill newborns. Anesthesiology 1981;54:423-5.

5 Friesen RH, Lichtor JL. Indirect measurement of blood pressure in neonates and infants utilizing an automatic noninvasive oscillometric monitor. Anesth Analg 1981;60:742-5.

${ }^{6}$ Lui K, Doyle PE, Buchanan N. Oscillometric and intra-arterial blood pressure measurements in the neonate: a comparison of methods. Aust Paediatr J 1982;18:32-4.

7 Pellegrini-Caliumi G, Agostino R, Nodari S, Maffei G, Moretti C, Bucci G. Evaluation of an automatic oscillometric method and of various cuffs for the measurement of arterial pressure in the neonate. Acta Paediatr Scand 1982;71:791-7.

8 Butt WW, Whyte HW. Blood pressure monitoring in neonates: comparison of umbilical and peripheral artery catheter measurements. J Pediatr 1984;105:630-2.

Correspondence to Dr M I Levene, Department of Child Health, Leicester Royal Infirmary, Leicester LE2 7LX, England.

Received 25 April 1986 